\title{
Ontogenia e estrutura do pericarpo de Prestonia riedelii (Müll. Arg.) Markgr. (Apocynaceae)
}

\author{
Shesterson Aguiar, Sandra Maria Carmello-Guerreiro² e Luiza Sumiko Kinoshita ${ }^{2}$
}

\author{
Recebido em 26/11/2007. Aceito em 31/10/2008
}

RESUMO - (Ontogenia e estrutura do pericarpo de Prestonia riedelii (Müll. Arg.) Markgr. (Apocynaceae)). O trabalho teve por objetivos descrever a ontogenia e estrutura do pericarpo de P. riedelii, visando fornecer subsídios aos trabalhos taxonômicos, filogenéticos e ecológicos realizados para família. Flores e frutos em diferentes estádios de desenvolvimento foram fixados em FAA, incluídos em resina plástica, seccionados com 10 ìm e corados com azul de toluidina para análise estrutural. O fruto de $P$. riedelii é um folicarium, sendo formado por dois frutículos do tipo folículo. O epicarpo, originado da epiderme externa do ovário, é formado por uma camada de células epidérmicas de cutícula espessa e tricomas tectores multicelulares e unisseriados. O mesocarpo, originado a partir do desenvolvimento do tecido fundamental, é formado por várias camadas de células parenquimáticas, feixes vasculares, fibras não lignificadas e laticíferos. O endocarpo sensu lato é formado por duas camadas de esclerócitos de disposição cruzada, que se originam da epiderme interna do ovário e de uma camada de células do tecido fundamental. A deiscência de cada folículo é marginal e o processo de deiscência envolve um conjunto de características anatômicas, como células de parede delgada e sinuosa formando a linha de deiscência, fibras não lignificadas no mesocarpo e esclerócitos de disposição cruzada no endocarpo.

Palavras-chave: anatomia, Apocynaceae, fruto, pericarpo, Prestonia

ABSTRACT - (Pericarp ontogeny and structure of Prestonia riedelii (Müll. Arg.) Markgr. (Apocynaceae)). The aim of this work was to describe the morphology and ontogeny of $P$. riedelii fruits to aid in taxonomic, ecological and phylogenetic studies in Apocynaceae. Fruits were fixed in FAA, embedded in plastic resin, sectioned at $10 \mathrm{imm}$ and stained with toluidine blue, for structural analysis. The fruit of $P$. riedelii is a follicarium, with two follicular fruitlets. The epicarp is one-cell-layered, with trichomes and thick cuticle. The mesocarp, originating from fundamental ovary tissue, is parenchymatous with laticifers, non-lignified fibers and vascular bundles. The endocarp sensu lato is two-celllayered of crossed sclereids, originating from the inner ovary epidermis and from a single layer of parenchyma cells of fundamental ovary tissue. Follicle dehiscence is lateral and the dehiscence process involves anatomical characteristics such as a dehiscence zone with thin-walled cells, non-lignified fibers in the mesocarp and crossed sclereids in the endocarp.

Key words: anatomy, Apocynaceae, fruit, pericarp, Prestonia

\section{Introdução}

Um dos maiores problemas no estudo de frutos é a escassa literatura específica sobre o assunto e a grande confusão nas terminologias utilizadas. O primeiro deles é a própria definição do termo fruto. A definição mais conhecida é a proposta por Gaertner (1788), que descreveu o fruto como sendo o "ovário desenvolvido" dos vegetais. No entanto esta definição dificulta e exclui da classificação os frutos que apresentam partes florais acessórias na sua formação (Roth 1977). Assim sendo, numa definição mais atual, Spjut (1994) considera fruto como sendo uma unidade propagativa, originada de partes carpelares e extracarpelares e Souza (2006) considera o fruto como sendo o ovário ou ovários desenvolvidos e em estado de maturação, podendo se agregar a ele outras partes da flor ou mesmo da inflorescência. Outro problema encarado pelos pesquisadores é a grande quantidade de termos utilizados na tipificação dos frutos. Para Barroso et al. (1999) este assunto é o mais complexo compreendido na Morfologia Vegetal. Linnaeus (1751) classificou os frutos em oito tipos básicos, entretanto nos dias atuais mais de cento e cinqüenta nomes têm sido propostos para classificar os diferentes tipos de frutos (Spjut 1994).

Apocynaceae sensu lato é uma das maiores e mais representativas famílias de Angiospermas, contendo em seus limites atuais cerca de 335 gêneros e 3.700 espécies (Judd et al. 2002), incluindo espécies de diversos hábitos, como árvores, arbustos, lianas e poucas ervas (Kinoshita 2005). Segundo Endress \& Bruyns (2000) o gênero Prestonia R. Br. pertence à tribo Echitae, circunscrita na subfamília Apocynoideae. Conhecida popularmente como cipó-capahomem, Prestonia riedelii (Müll. Arg.) Markgr. é uma espécie encontrada em regiões de floresta estacional semidecídua, clareiras, regiões degradadas e matas ciliares (Rio \& Kinoshita 2005). Seus frutos são foliculares (Rio \& Kinoshita 2005) e abrigam diversas sementes comosas. Apesar de existirem diversos trabalhos relacionados à anatomia de frutos em Apocynaceae (Mahran et al. 1967; Castro 1986; Dave \& Kuriachen 1990; Kuriachen et al. 1990; Dave \& Kuriachen 1991; Kuriachen et al. 1991; Thomas \& Dave 1991; Kuriachen et al. 1992; Souza \& Moscheta 1992; Thomas \& Dave 1994; Souza et al. 2004) em nenhum deles encontra-se descrições de representantes do gênero.

Características anatômicas de frutos têm sido sempre negligenciadas em estudos sistemáticos porque são tecnicamente difíceis de serem investigadas (Bobrov et al. 2005), no entanto elas podem ter uma grande importância em trabalhos taxonômicos (Hutchinson 1969), pois, segundo Von Teichman \& Wyk (1991), apresentam pequena plasticidade fenotípica. Em um trabalho recente Potgieter \& Albert (2001) utilizaram características moleculares e dos

\footnotetext{
1 Parte da Dissertação de Mestrado do primeiro Autor

2 Universidade Estadual de Campinas, Departamento de Botânica, Campinas, SP, Brasil

3 Autor para correspondência: smcg@unicamp.br
} 
propágulos (frutos e sementes) de espécies de Apocynaceae para investigar as relações fillogenéticas existentes na família. No entanto, as características sugeridas pelos autores, como esclerificação do pericarpo, espessura do exocarpo e consistência do mesocarpo foram baseadas apenas em observações morfológicas dos frutos, e não em descrições anatômicas. Desta forma, um estudo das características anatômicas dos frutos de $P$. riedelii é de fundamental importância para complementar e auxiliar nos estudos taxonômicos, filogenéticos e ecológicos na família, sendo, portanto, o principal objetivo do presente trabalho.

\section{Materiais e métodos}

O material botânico de Prestonia riedelii (Müll. Arg.) Markgr. foi coletado de populações da Reserva Biológica do Laboratório Nacional de Luz Sincrontron, Campinas, SP, Brasil e da Reserva Biológica da Campininha, Mogi Mirim, SP, Brasil. O material constou de flores, frutos e sementes em vários estádios de desenvolvimento. Uma parte do material foi fixada em FAA (Johansen 1940) e conservada em álcool etílico $70 \%$. A outra parte do material permaneceu fresca e foi utilizada para estudos morfológicos. Para o estudo anatômico o material conservado foi incluído em resina plástica (Gerrits \& Smid 1983), seccionado em micrótomo rotativo e as secções, de 10 ìm de espessura, foram coradas com azul de toluidina (O'Brien et al. 1964). Para a análise histoquímica foram utilizados os seguintes corantes e reagentes: Sudan black B (Pearse 1980), para a detecção de substâncias lipofílicas presentes na cutícula, reagente de lugol (Jensen 1962), para a detecção de amido no pericarpo do fruto e floroglucina acidificada (Johansen 1940), para detecção de lignina. Para a descrição dos resultados utilizou-se a terminologia de Roth (1977) e Spjut (1994). As fotomicrografias foram realizadas em microscópio Olympus BX 51 e as escalas obtidas nas mesmas condições ópticas. As exsicatas foram devidamente identificadas e inseridas no acervo do herbário do Departamento de Botânica - Instituto de Biologia - UNICAMP (UEC): $P$. riedelii (Müll. Arg.) Markgr.: BRASIL. São Paulo: Campinas, 24/V/2001, S. Aguiar (3), 118807 (UEC); Mogi Mirim, 1/III/2002, S. Aguiar (27), 127249 (UEC).

\section{Resultados}

Morfologia - $\mathrm{O}$ fruto de $P$. riedelii é do tipo folicarium (folículo esquizocárpico), pois é constituído de dois frutículos (frutéolos) cilíndricos e alongados do tipo folículo (Fig. 1), unidos pela região basal (receptacular) e pela região apical. Os folículos jovens são indumentados (Fig. 6) e de coloração verde. À medida que os folículos amadurecem parte dos indumentos (tricomas tectores) cai (Fig. 11), permanecendo somente poucos no pericarpo do fruto (Fig. 15). Quando maduros os folículos tornam-se secos, de cor marrom e deiscentes por uma única sutura longitudinalmarginal, expondo várias sementes comosas. Os folículos permanecem unidos pela região apical (Fig. 1) durante uma boa parte do desenvolvimento, mas depois se separam e tornam-se levemente divergentes.

Os folículos desenvolvem-se de um ovário súpero, bicarpelar, bilocular, sincárpico e de placentação sutural (Fig. 2, 4). Na base do ovário estão presentes nectários, bem desenvolvidos e visíveis a olho nu, e coléteres deltóides, alternos aos nectários e opostos às lacínias do cálice (Fig. 2, 4). Os carpelos apresentam-se ligados pelas regiões basal e terminal do ovário e pelos estiletes e estigmas, estando livres somente na região mediana do ovário (Fig. 2, 4). Cada carpelo apresenta um único lóculo onde se encontram vários óvulos inseridos em um tecido placentário bem desenvolvido (Fig. 2, 4). Após a fertilização a corola e o cálice caem e cada carpelo desenvolve-se em um folículo.

Anatomia - Parede do ovário - Anatomicamente a parede do ovário, em cada um dos carpelos, é constituída de uma epiderme externa, do tecido fundamental e de uma epiderme interna (Fig. 3, 5)

As epidermes externa e interna do ovário são unisseriadas (Fig. 3, 5), com células de citoplasma abundante, núcleo esférico de posição central e cutícula delgada. A epiderme externa apresenta células cubóides ou levemente colunares (Fig. 5), enquanto que na epiderme interna as células são levemente retangulares (Fig. 5).

O tecido fundamental é formado por cerca de 30 camadas de células parenquimáticas em meio às quais são encontrados laticíferos e feixes vasculares (Fig. 3, 5). Os laticíferos são cilíndricos, alongados (Fig. 3), algumas vezes ramificados, de conteúdo denso e de parede espessa, sendo facilmente diferenciados das demais células parenquimáticas do mesocarpo (Fig. 3, 5). Os feixes vasculares estão dispersos na região mediana de todo tecido fundamental, sendo três de maior calibre: um dorsal (Fig. 5) e dois ventrais. A linha de deiscência não é muito evidente, mas pode ser notada por uma reentrância na região de sutura dos carpelos, onde se observam células de citoplasma denso e paredes sinuosas. A placenta é bem desenvolvida (Fig. 2, 4) com inúmeros feixes vasculares que irão irrigar os óvulos.

Pericarpo - Com base nas alterações anatômicas que ocorrem durante o desenvolvimento do fruto, como aparecimento de tricomas no epicarpo, diferenciação das fibras no mesocarpo, lignificação das células do endocarpo e deiscência, foram utilizados três estádios de desenvolvimento para descrever o pericarpo: estádio I -

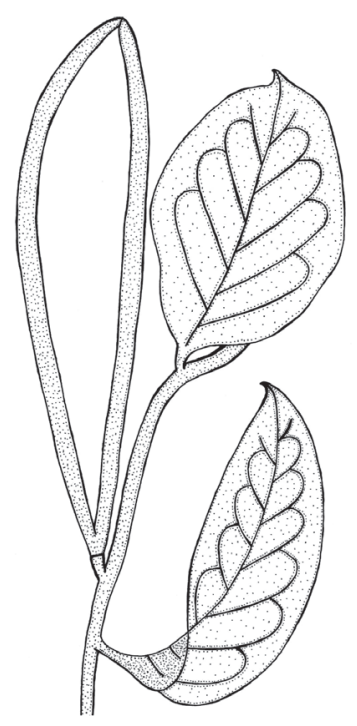

Figura 1. Prestonia riedelii (Müll. Arg.) Markgr. Detalhe do ramo com fruto. 
fruto jovem, estádio II - fruto maduro e estádio III - fruto deiscente. Para melhor entendimento, o pericarpo dos frutos foi dividido em três regiões anatômicas claramente diferenciadas em todos os estádios de desenvolvimento: epicarpo, mesocarpo e endocarpo.

Estádio I - O epicarpo, derivado exclusivamente da epiderme externa do ovário, é constituído por uma camada de células cúbicas (Fig. 8) de núcleos proeminentes e centrais, recobertas por fina cutícula e por tricomas tectores multicelulares e unisseriados (Fig. 6). Os tricomas são originados a partir do alongamento (Fig. 8) e divisões periclinais das células epidérmicas dos frutos em desenvolvimento, pois não estão presentes no ovário.

O mesocarpo se desenvolve a partir do tecido fundamental do ovário e é constituído por 30 a 35 camadas de células parenquimáticas, feixes vasculares, ilhas de floema, laticíferos e fibras em diferenciação (Fig. 6). Durante o desenvolvimento dos frutos ocorre um aumento no número de células que compõem o mesocarpo, devido a divisões, em vários planos, das células que o constituem. Neste estádio as células parenquimáticas apresentam ligeira diferenciação conforme a região onde são encontradas (Fig. 6). As que se localizam próximas ao epicarpo são menores e possuem parede pecto-

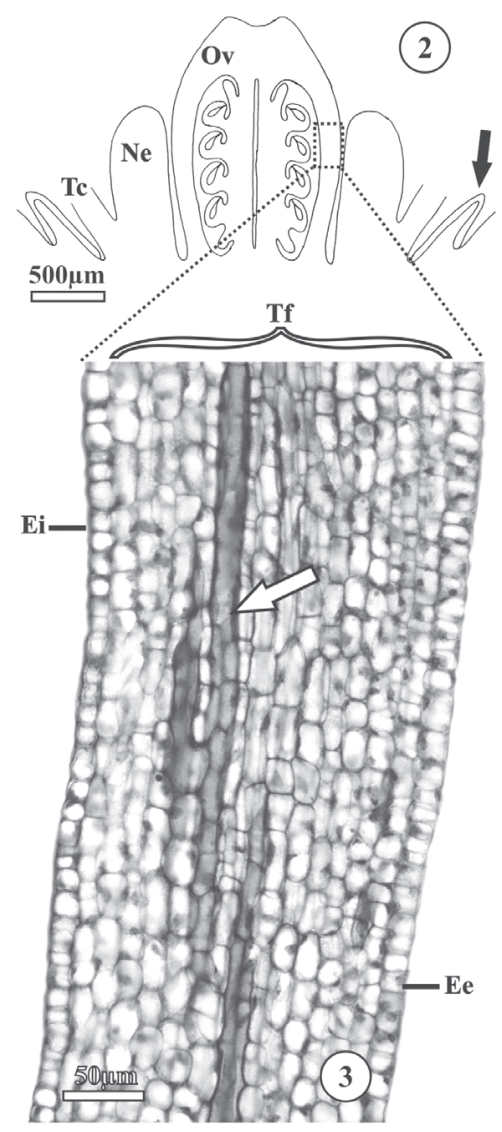

Figuras 2-3. Secção longitudinal da flor e do ovário de Prestonia riedelii (Müll. Arg.) Markgr. 2. Esquema da flor, mostrando a disposição dos coléteres (seta), tudo da corola, nectários e ovário. 3. Fotomicrografia da parede do ovário $($ seta $=$ laticífero alongado). Ee = epiderme externa do ovário; $\mathrm{Ei}=$ epiderme interna do ovário; $\mathrm{Ne}=$ nectário; $\mathrm{Ov}=$ ovário; $\mathrm{Tc}=$ tubo da corola; $\mathrm{Tf}=$ tecido fundamental

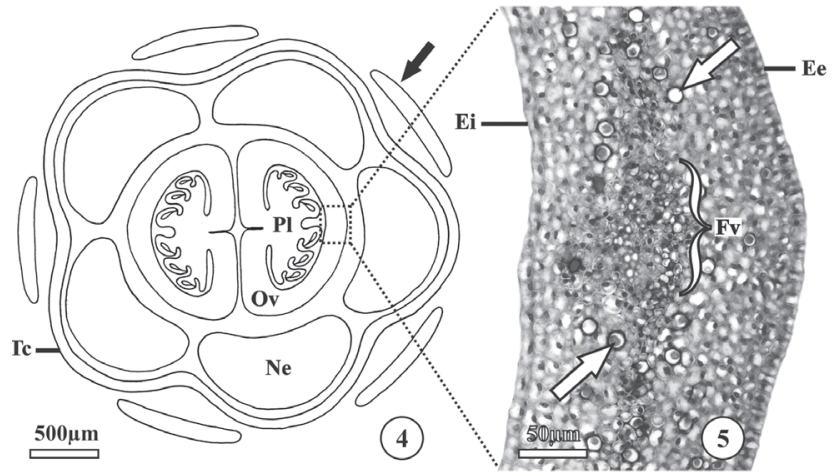

Figuras 4-5. Secção transversal da flor e ovário de Prestonia riedelii (Müll. Arg.) Markgr. 4. Esquema da flor, mostrando a disposição dos coléteres (seta), tubo da corola, nectários, ovário e placenta. 5. Fotomicrografia da parede do ovário (setas $=$ laticíferos). Ee = epiderme externa do ovário; $\mathrm{Ei}=$ epiderme interna do ovário $; \mathrm{Fv}=$ feixe vascular; $\mathrm{Ne}=$ nectário $; \mathrm{Ov}=$ ovário $; \mathrm{Pl}=$ placenta; $\mathrm{Tc}=$ tubo da corola

celulósica ligeiramente espessada (Fig. 6), ao passo que as que se localizam próximas ao endocarpo são maiores e possuem parede pecto-celulósica delgada (Fig. 6).

Na região mediana do mesocarpo podem ser distinguidos feixes vasculares, parcialmente diferenciados (Fig. 6), ilhas de floema e fibras em diferenciação. As fibras em diferenciação são derivadas de células parenquimáticas que se alongam (Fig. 9) e iniciam a deposição de parede secundária.

Os laticíferos estão distribuídos por todo o mesocarpo do fruto, espalhados entre as células parenquimáticas (Fig. $6,8)$. Possuem formato cilíndrico e alongado, e podem ser facilmente reconhecidos pela parede pecto-celulósica levemente espessada (Fig. 8) ou pelo conteúdo denso que apresentam.

Os feixes vasculares se distribuem na região mediana do mesocarpo e estão parcialmente diferenciados neste estádio de desenvolvimento (Fig. 6), pois são reconhecidos somente alguns elementos traqueais no xilema e poucas células companheiras no floema (Fig. 6). Já as ilhas de floema, localizadas próximas aos feixes vasculares, possuem somente algumas células companheiras diferenciadas.

O endocarpo é constituído por duas camadas de células (Fig. 6, 7,10). Neste estádio estas duas camadas apresentam parede delgada e são facilmente distinguidas, pois as células externas, originadas da epiderme interna do ovário, são levemente alongadas no sentido transversal (Fig. 7) e as células internas, originadas do tecido fundamental do ovário, levemente alongadas no sentido longitudinal do fruto (Fig. 10).

Estádio II - O epicarpo ainda encontra-se unisseriado (Fig. 11,14, 15), mas as células que o constituem apresentam espessamento pecto-celulósico de parede (Fig. 14), principalmente a periclinal externa. A cutícula, mais espessa (Fig. 14), apresenta pequenas ondulações e também pode ser vista recobrindo os tricomas tectores (Fig. 15). Os tricomas (Fig. 15) são menos abundantes, pois ocorre deiscência dos mesmos à medida que o fruto vai 

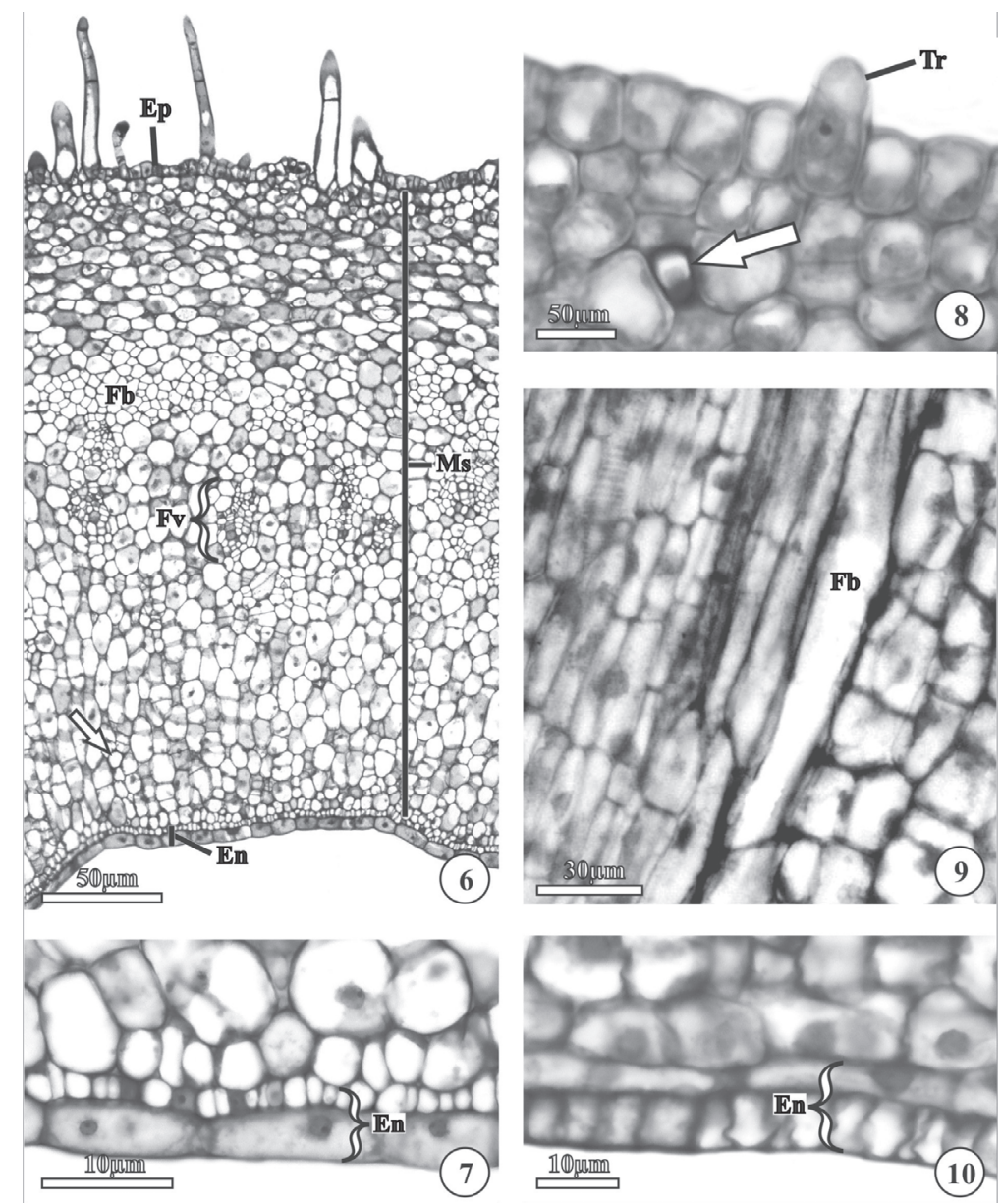

Figuras 6-10. Secç̃es do fruto jovem de Prestonia riedelii (Müll. Arg.) Markgr. 6-8. Secções transversais. 9-10. Seções longitudinais. 6. Visão geral do pericarpo do fruto. 7. Detalhe do início da formação do endocarpo. 8. Detalhe do epicarpo evidenciando o início da formação de um tricoma (seta $=$ laticífero). 9. Fibras em fase de diferenciação. 10. Detalhe do início da formação do endocarpo. $\mathrm{En}=$ endocarpo; $\mathrm{Ep}=$ epicarpo; $\mathrm{Fb}=$ fibra; $\mathrm{Ms}=$ mesocarpo; $\mathrm{Tr}=$ tricoma.

amadurecendo, havendo várias regiões do epicarpo onde eles não são encontrados (Fig. 11).

No mesocarpo a distinção entre as células parenquimáticas que o constituem torna-se mais nítida (Fig. 11). As 10 primeiras camadas de células parenquimáticas, localizadas entre o epicarpo e o anel de fibras, são pequenas, de parede pecto-celulósica levemente espessada e protoplasto rico em grãos de amido (Fig. 14). Já as demais camadas de células parenquimáticas, localizadas entre localizadas entre o anel de fibras e o endocarpo, com exceção da última, são maiores e possuem paredes delgadas (Fig. 11). A última camada de células parenquimáticas do mesocarpo, em contato direto com o endocarpo, é formada por células pequenas, de paredes delgadas e sinuosas (Fig. 11, 13) e são facilmente distinguidas.

As fibras, originadas a partir da diferenciação de células parenquimáticas do fruto jovem (Fig. 9), encontram-se totalmente diferenciadas. São alongadas no sentido longitudinal do fruto (Fig. 17) e formam um anel periférico, quase que contínuo, por todo o mesocarpo (Fig. 11), sendo também encontradas próximas aos feixes vasculares (Fig. 12) e linha de deiscência (Fig. 18). Possuem parede secundária extremamente espessada e sem pontuações (Fig. 12, 17, 18), com um padrão diferente do esperado para este tipo celular, pois apresentam coloração púrpura (Fig. 11, 12, 17, 18) e não verde ao ser corada com azul de toluidina. Com a realização do teste de floroglucina acidificada, foi constatada a ausência de lignina na parede das fibras e confirmada a natureza pecto-celulósica da mesma. Em algumas fibras constatou-se a presença de núcleo e nucléolo (Fig. 18), mostrando que ainda estão vivas neste estádio de desenvolvimento.

Os feixes vasculares, agora totalmente diferenciados (Fig. 12), se distribuem na região mediana do mesocarpo (Fig. 11), internamente ao anel de fibras. Podem ser colaterais ou bicolaterais (Fig. 12), e possuem floema formado por células companheiras de citoplasma bem denso (Fig. 12), sendo facilmente diferenciadas dos elementos de tubo crivado. As ilhas de floema (Fig. 11) são mais distinguíveis do que no estádio anterior e ocorrem próximas aos feixes vasculares.

Os laticíferos, abundantes por todo o mesocarpo do fruto (Fig. 11), são mais fáceis de serem identificados devido ao aumento pecto-celulósico da parede, que é mais pronunciado nos ângulos de contato entre as células parenquimáticas 
que o circundam (Fig. 12). Também podem ser identificados pelo formato cilíndrico (Fig. 12) e alongado (Fig. 16) que apresentam ou pelo conteúdo denso (Fig. 16), quando presente.

Durante o amadurecimento do fruto as duas camadas de células do endocarpo produzem parede secundária extremamente espessada, diferenciando-se em esclerócitos (Fig. 11, 13). Estes esclerócitos são lignificados, pois reagem em verde com azul de toluidina (Fig. 11, 13) e em vermelho com floroglucina acidificada. Estas células possuem alongamento em orientações diferentes (Fig. 13), pois a camada mais interna, originada da epiderme interna do ovário, se alonga no sentido transversal e a camada mais externa, originada do tecido fundamental, se alonga no sentido longitudinal, ou seja, tem disposição cruzada (Fig. 13).

Estádio III - Corresponde ao estádio onde o fruto perde água e torna-se deiscente. A deiscência ocorre ao longo de uma única sutura marginal, que anatomicamente é denominada região de deiscência. Esta região, localizada na margem de união dos carpelos, é formada por fibras não lignificadas, feixes vasculares e células parenquimáticas de parede delgada e contorno sinuoso, que formam a linha de deiscência (Fig. 17). Durante a secagem natural dos frutos as células parenquimáticas e as fibras não lignificadas do mesocarpo perdem muita água, colapsam e fazem com que ocorra um encolhimento do pericarpo. Durante este processo de perda de água as tensões diferentes provocadas pela disposição cruzada das células do endocarpo, fazem

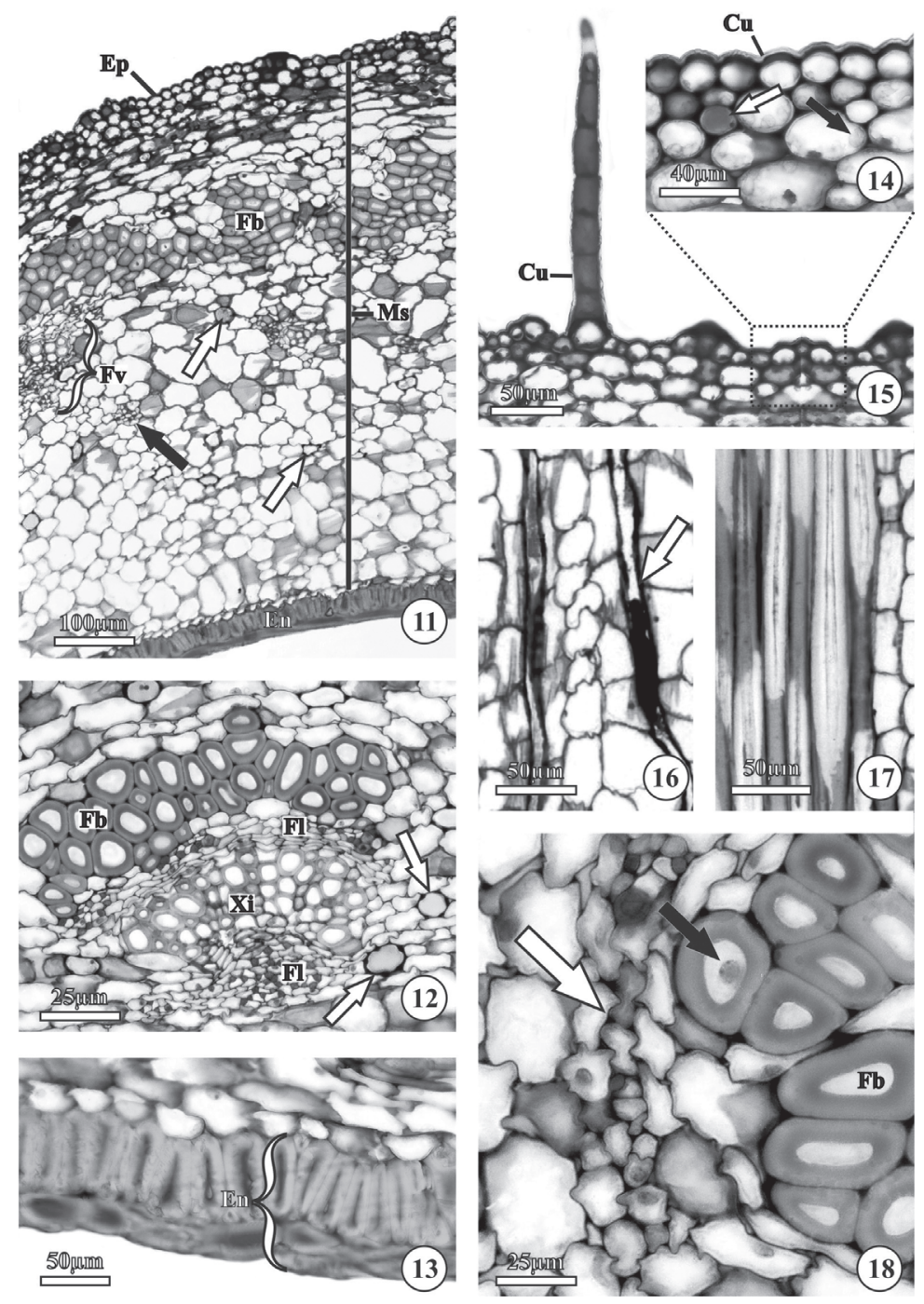

Figuras 11-18. Secções do fruto maduro de Prestonia riedelii (Müll.Arg.) Markgr. 11-15, 18. Secções transversais. 16 - 17. Secções longitudinais. 11. Visão geral do pericarpo do fruto (setas brancas = laticíferos; seta preta = ilha de floema). 12. Feixe vascular bicolateral, fibras e laticíferos (setas). 13. Detalhe do endocarpo do fruto. 14. Detalhe do epicarpo, evidenciando cutícula e parede periclinal externa das células epidérmicas espessada, e das células parenquimáticas do mesocarpo com grãos de amido (seta preta). Observar a presença de laticífero com conteúdo denso (seta branca). 15. Epicarpo com tricoma tector. 16. Detalhe do laticífero (seta) com conteúdo denso. 16. Detalhe das fibras. 17. Linha de deiscência (seta) e fibras do mesocarpo. $\mathrm{Cu}=$ cutícula; En = endocarpo; Ep = epicarpo; Fb = fibras; $\mathrm{Fl}=$ floema; $\mathrm{Fv}=$ feixe vascular, $\mathrm{Ms}=$ mesocarpo; $\mathrm{Xi}=$ xilema . 
com que o pericarpo tenha uma torção com conseqüente ruptura das células na região da linha de deiscência, promovendo a abertura do fruto.

\section{Discussão}

Segundo Roth (1977) a classificação dos frutos ainda é um problema não solucionado. Muitos caracteres diferentes, tais como estrutura do ovário, número de carpelos e sementes, morfologia e anatomia do fruto, dispersão dos frutos e sementes, deiscência e consistência do pericarpo são utilizados na caracterização dos diferentes tipos de frutos. Todavia, o que ocorre freqüentemente é que alguns autores introduzem subtipos de menor importância na classificação gerando muita confusão.

Endress \& Bruyns (2000) citam a existência de folículos tipicamente delgados para a tribo Echitae, à qual pertence $o$ gênero Prestonia, da mesma forma que Rio \& Kinoshita (2005) citam a existência de frutos do tipo folículo para $P$. riedelii. Neste trabalho adotou-se a terminologia folicarium, proposta por Spujt (1994), para o fruto desta espécie. Segundo Spjut (1994) o termo folicarium representa o fruto derivado de gineceu esquizocárpico, no qual os carpelos são distintamente separados um do outro, sendo que cada um possui deiscência ao longo de uma única sutura ventral, como foi observado nos frutos de $P$. riedelii. De acordo com Spjut (1994) o termo folicarium foi descrito pela primeira vez por Dumortier (1835), tendo alguns sinônimos, como Conceptaculum Lindley (1832), Foliculi Gaertner (1788), Bifolliculus Mirbel (1813) e Follicula Desvaux (1813). Já o termo folículo refere-se a frutos unicarpelares que apresentam deiscência por uma única sutura ventral (Linnaeus 1759), sendo coerente denominar, portanto, cada um dos frutículos de $P$. riedelii de folículo e não o fruto como um todo. Pode ocorrer de somente um frutículo do gineceu esquizocárpico se desenvolver (Cronquist 1981), sendo, neste caso, chamado de folículo instalado em um folicarium (Spjut 1994). Barroso et al. (1999) classifica os frutos das Apocynaceae como múltiplos, quando originados de gineceu com apocarpia secundária, e de simples, quando originados de gineceu sincárpico. Frutos semelhantes ao da espécie estudada neste trabalho são classificados por Barroso et al. (1999) como múltiplos do tipo folículo.

Para que ocorra uma coerente classificação dos frutos é necessário que haja estudos anatômicos de seu desenvolvimento. A parede do fruto, desta forma, é dividida anatomicamente em três regiões: epicarpo, mesocarpo e endocarpo. De acordo com Fahn (1990), a separação serve para facilitar a descrição anatômica, sendo que a definição destes termos varia conforme cada autor. A maioria dos autores modernos prefere usar os termos epicarpo e endocarpo em seu sentido mais amplo (sensu lato), que inclui na sua formação além das epidermes externa e interna, respectivamente, também células do tecido fundamental ovariano (Roth 1977).

De acordo com Roth (1977) o epicarpo representa a camada mais externa do pericarpo. Epicarpo unisseriado foi observado no pericarpo de $P$. riedelii que, segundo sua origem, pode ser classificado como epicarpo sensu stricto, assim como observado em Calotropis procera (Ailton) W. T. Ailton (Mahran et al. 1967), Catharanthus roseus G. Don (Zala et al. 1976), Araujia hortorum E. Fourn. (Castro 1986), Pergularia daemia (Forssk.) Chiov. (Kuriachen \& Dave 1989), Asclepias curassavica L. (Dave \& Kuriachen 1990), C. procera (Kuriachen et al. 1991), Calotropis gigantea W.T. Aiton (Kuriachen et al. 1992), Aspidoperma polyneuron Müll. Arg. (Souza \& Moscheta 1992), e várias espécies de Apocynaceae (Thomas \& Dave 1994). Segundo Roth (1977) a epiderme externa dos frutos geralmente é unisseriada e representa a camada protetora. No entanto a presença de epicarpo unisseriado nos frutos não é válida para todas as espécies da família, pois foi observado epicarpo multisseriado em Tylophora dalzellii Hook. f. (Kuriachen et al. 1990), Nerium indicum Mill. (Thomas \& Dave 1991) e algumas espécies de Apocynaceae (Thomas \& Dave 1994), sendo que em todas estas espécies o epicarpo é considerado sensu lato, pois é formado por uma camada de células epidérmicas e camadas subseqüentes de células colenquimatosas e/ou esclerenquimáticas subepidérmicas. Somente em Aganosma caryophyllata G. Don (Thomas \& Dave 1994) observa-se epicarpo multisseriado sensu stricto.

A superfície dos frutos sempre se encontra recoberta por cutícula, sendo a sua formação influenciada por vários fatores como luz, temperatura, entre outros (Roth, 1977). Cutícula espessa é um caráter muito comum em frutos de Apocynaceae (Mahran et al. 1967; Zala et al. 1976; Castro 1986; Kuriachen \& Dave 1989; Kuriachen et al. 1990; Dave \& Kuriachen 1991; Kuriachen et al. 1991; Thomas \& Dave 1991; Souza \& Moscheta 1992; Kuriachen et al. 1993; Thomas \& Dave 1994) e também foi observado nos folículos de $P$. riedelii. A cutícula possui papel fundamental na diminuição da perda de água para o ambiente (Thomas \& Dave, 1994), sendo esta função de grande importância em $P$. riedelii visto que esta planta está submetida a altas intensidades luminosas, pois geralmente é encontrada em encostas e bordas de matas. Estriações cuticulares estão presentes em folículos de C. procera (Mahran et al. 1967; Dave \& Kuriachen 1987), A. curassavica (Dave \& Kuriachen 1990), T. dalzellii (Kuriachen et al. 1990), C. gigantea e Tylophora indica Merr. (Kuriachen et al. 1992), mas não foram encontradas em $P$. riedelii.

Tricomas de cobertura multicelulares e unisseriados foram observados no epicarpo de $P$. riedelii, assim como em C. procera (Mahran et al. 1967; Dave \& Kuriachen 1987), C. roseus (Zala et al. 1976), A. hortorum (Castro 1986), P. daemia (Kuriachen \& Dave 1989), A. caryophyllata, Ichnocarpus frutescens $\mathrm{R}$. Br. e Wrightia tinctoria $\mathrm{R}$. Br. (Thomas \& Dave 1994), tendo provável função de contribuir para a redução da transpiração. Já em C. roseus, Parsonsia spiralis Wall. e Vallaris solanacea Kuntze encontram-se tricomas unicelulares (Thomas \& Dave 1994).

As funções desempenhadas pelos estômatos nos frutos são a de controle da temperatura e controle do balanço 
hídrico através da evaporação (Roth 1977). Estômatos foram observados em vários exemplares da família (Mahran et al. 1967; Zala et al. 1976; Dave \& Kuriachen 1987; Kuriachen \& Dave 1989; Kuriachen et al. 1990; Dave \& Kuriachen 1991; Kuriachen et al. 1991; Thomas \& Dave 1991; Kuriachen et al. 1992; Thomas \& Dave 1994), sendo classificados como paracíticos, anomocíticos ou ciclocíticos. Em A. polyneuron (Souza \& Moscheta 1992), e espécies de Parsonsia R. Br. e Strophanthus A. DC. (Thomas \& Dave 1994) os estômatos são substituídos por lenticelas. Em $P$. riedelii não foram observados estômatos de nenhum dos tipos citados. A ausência de estômatos não é exclusiva da espécie estudada neste trabalho, pois já foi mencionada para outras espécies da família por Kuriachen et al. (1992) e por Thomas \& Dave (1994).

No pericarpo de $P$. riedelii encontram-se fibras formando um tecido quase que contínuo no mesocarpo e próximo aos feixes vasculares do fruto maduro. Estas fibras apresentam estrutura ligeiramente diferente da usualmente encontrada neste tipo celular, pois possuem parede secundária de espessamento predominantemente pecto-celulósico e ausência de lignina, estando, desta forma, relacionadas com a ligeira flexibilidade apresentada pelo fruto maduro. Kuriachen et al. (1992) denominaram estas células de fibras celulósicas ao estudar frutos de espécies da família. A presença de lignina não é uma condição indispensável para as fibras, pois Esau (1965) afirma que as fibras extraxilemáticas podem ou não se apresentar lignificadas. Estas células foram reconhecidas como fibras pelo espessamento secundário da parede, pelo formato alongado e pela ausência de pontuações. Fibras com as mesmas características também foram encontradas em C. procera (Mahran et al. 1967 e Kuriachen et al. 1991), T. dalzelii (Kuriachen et al. 1990), N. indicum (Thomas \& Dave 1991) e várias espécies estudadas por Kuriachen et al. (1992) e por Thomas \& Dave (1994), sendo que em grande parte destas espécies as fibras estão associadas aos feixes vasculares, formando uma bainha protetora. Segundo Roth (1977) as fibras no mesocarpo dos frutos atuam como um tecido de resistência, mas no caso de $P$. riedelii além desta função acredita-se que elas contribuam também para a deiscência do fruto por exibir grande capacidade de absorção e perda de água, criando uma tensão higroscópica no pericarpo.

Laticíferos são células (ou fileiras de células) espalhadas por todo o corpo da planta, contendo um fluido chamado látex (Esau 1965; Evert 2006), que possui uma composição química muito variada (Fahn 1979). Sua função é de proteger a planta contra herbivoria, microorganismos e também selar ferimentos (Fahn 1979; 1990; Farrell et al. 1991; Hunter 1994). Os laticíferos também se desenvolvem em frutos e já foram reportados em várias espécies como Ficus carica (Moraceae), Carica papaya (Caricaceae) e Papaver somniferum (Papaveraceae) (Roth 1977). Na família Apocynaceae diversos trabalhos citam a presença de laticíferos em frutos (Mahran et al. 1967; Castro 1986; Kuriachen \& Dave 1989; Kuriachen et al. 1990; Dave \&
Kuriachen 1991; Kuriachen et al. 1991; Thomas \& Dave 1991; Kuriachen et al. 1992; Souza \& Moscheta 1992; Thomas \& Dave 1994; Souza et al. 2004). Em P. riedelii os laticíferos são localizados por todo o mesocarpo do fruto e apresentam parede pecto-celulósica espessada, principalmente nos ângulos de contato com as células parenquimáticas que o margeiam, e conteúdo denso. A maioria dos trabalhos de frutos em Apocynaceae descreve os laticíferos como sendo não-articulados (Castro 1986; Kuriachen \& Dave 1989; Kuriachen et al. 1990; Dave \& Kuriachen 1991; Kuriachen et al. 1991; Thomas \& Dave 1991; Kuriachen et al. 1992; Thomas \& Dave 1994; Souza et al. 2004; Aguiar et al. 2008) sem realizar em estudo ontogenético detalhado dos mesmos. Segundo Demarco et al. (2006) os laticíferos de Aspidosperma australe Mull. Arg. e Blepharodon bicuspidatum E. Fourn. são articulados, pois foi verificado, em estádios iniciais de desenvolvimento, adição de células nos laticíferos. Desta forma pode-se concluir que para classificar os laticíferos corretamente deve-se realizar um estudo detalhado do desenvolvimento dos mesmos. No presente trabalho, apesar de ter sido realizado estudo ontogenético nos frutos de $P$. riedelii, não ficou conclusiva a origem dos laticíferos nos mesmos, sendo este o motivo pelo qual se optou por não mencionar sua origem.

O endocarpo, segundo Roth (1977) pode se originar da epiderme interna do ovário (endocarpo sensu stricto), somente das camadas sub-epidérmicas do tecido fundamental ovariano, ou ainda da combinação de ambas (endocarpo sensu lato). Em $P$. riedelii o endocarpo desenvolve-se a partir da epiderme interna do ovário e de uma camada sub-epidérmica interna do tecido fundamental ovariano. A lignificação do endocarpo ocorre somente no fruto maduro, auxiliando desta forma o crescimento das sementes no interior do fruto. Segundo (Potgieter \& Albert 2001) a presença de endocarpo lignificado seria uma característica primitiva em Apocynaceae e foi descrita em várias espécies, como Rauvolfia serpentina Benth. ex Kurz (Gupta \& Lamba 1981), T. dalzellii (Kuriachen et al. 1990), C. procera (Kuriachen et al. 1991), N. indicum (Thomas \& Dave 1991), A. polyneuron (Souza \& Moscheta 1992), espécies de Asclepiadaceae sensu stricto (Kuriachen et al. 1992), e espécies de Apocynaceae (Thomas \& Dave 1994). A estrutura do endocarpo de $P$. riedelii revelou semelhante estrutura com as demais espécies já estudadas na família. Neste trabalho foi adotado o termo esclerócito para caracterizar as células que formam o endocarpo, devido à quantidade de pontuações, ao formato irregular e curto tamanho apresentado pelas células, mas em grande parte das espécies já estudadas da família Apocynaceae o tipo celular mais citado para o endocarpo dos frutos são as fibras. Nos trabalhos de Zala et al. (1976), Kuriachen et al. (1991), Thomas \& Dave $(1991 ; 1994)$ é citada e presença de células lignificadas ou esclerenquimáticas no endocarpo dos frutos, sem mencionar o tipo celular apresentado por elas. Gupta \& Lamba (1981) citam vários tipos de esclerócitos presentes no endocarpo de $R$. serpentina (macroesclerócitos, 
braquiesclerócitos, esclerócitos filiformes e esclerócitos fusiformes), mas como neste trabalho não foi realizado macerado no endocarpo de $P$. riedelii não se pode chegar a nenhuma conclusão quanto ao tipo de esclerócito que forma o mesmo. Castro (1986) e Souza \& Moscheta (1992) também citam a presença de esclerócitos no endocarpo das espécies estudadas.

As células do endocarpo de $P$. riedelii apresentam disposição cruzada, sendo a camada em contato com as sementes originada da epiderme interna do ovário e a camada em contato com o mesocarpo originada de células subepidérmicas do tecido fundamental ovariano. O endocarpo de $P$. riedelii, portanto, é considerado sensu lato, assim como na maioria dos folículos já estudados em espécies de Apocynaceae (Zala et al. 1976; Kuriachen et al. 1990; Thomas \& Dave 1991; Kuriachen et al. 1991; Kuriachen et al. 1992; Souza \& Moscheta 1992; Thomas \& Dave 1994). Thomas \& Dave (1991) encontraram cristais prismáticos, rombóides e drusas no endocarpo de $N$. indicum, ausentes no endocarpo de $P$. riedelii.

A deiscência dos folículos de $P$. riedelii ocorre ao longo das margens do carpelo. Antigamente este tipo de deiscência era chamado de ventral, mas Roth (1977) considera que este termo é inadequado, pois o lado ventral do carpelo corresponde à face interna deste. Assim sendo utilizou-se o termo deiscência marginal, sugerido por Roth (1977), para os folículos de P. riedelii, visto que a sutura se forma ao longo das margens do carpelo. Semelhante deiscência foi também retratada em C. procera (Mahran et al. 1967), C. roseus (Zala et al. 1976), Illicium floridanum Ellis e Cynanchum vincetoxicum Pers. (Roth 1977), Banksia L.f. (Wardrop 1983), A. hortorum (Castro 1986), T. dalzellii (Kuriachen et al.1990), N. indicum (Thomas \& Dave 1991), A. polyneuron (Souza \& Moscheta 1992) e em diversos frutos foliculares de diferentes famílias (Roth 1977).

Segundo Roth (1977) os mecanismos de deiscência são baseados, em geral, em movimentos de tecidos vivos e mortos. Dois tipos fundamentais de mecanismos de deiscência podem ocorrer: o higroscópico e o de turgor. Os higroscópicos dependem, geralmente, do encolhimento ou distenção das paredes de células mortas, enquanto que o de turgor funciona com células vivas, de paredes elásticas. No caso dos frutos de P. riedelii pode-se concluir que a deiscência é do tipo higroscópica xerocásica, visto que o pericarpo do fruto seca a medida que o fruto amadurece. Vários fatores auxiliam na abertura dos frutos, como a presença de uma linha de deiscência, formada por células de paredes delgadas, a ocorrência das fibras no mesocarpo e a lignificação do endocarpo. De acordo com Fahn e Zohary (1955) as fibras são células que apresentam grande capacidade de absorção e perda de água (inchaço e encolhimento), criando uma tensão higroscópica muito importante na abertura dos frutos. Desta forma acredita-se que as fibras do mesocarpo de $P$. riedelii sejam muito importantes para a abertura dos folículos, corroborando com as observações de Thomas \& Dave (1994), que já haviam sugerido esta mesma função para as fibras encontradas nos frutos das espécies estudadas por eles. As células lignificadas e de paredes altamente espessadas, presentes no endocarpo, também criam uma tensão higroscópica no fruto, contribuindo para o mecanismo de abertura.

Quanto à estrutura anatômica do pericarpo observou-se que a espécie apresenta o mesmo padrão geral dos folículos de espécies já estudadas na família, pois a presença de fibras não lignificadas no mesocarpo, laticíferos de parede pectocelulósica levemente espessada, linha de deiscência com células de parede delgada e endocarpo lignificado são características frequentemente ocorrentes. O estudo ontogenético do fruto ajudou a descrever, com mais precisão, a origem das camadas que compõem o pericarpo do fruto, principalmente a do endocarpo sensu lato, que apresenta origem mista. A aplicação do teste de floroglucina acidificada foi de fundamental importância para confirmar a natureza pecto-celulósica das paredes das fibras do mesocarpo, sendo um dado inédito para família.

\section{Agradecimentos}

Os autores agradecem à Coordenação de Aperfeiçoamento de Pessoal de Nível Superior (CAPES), pela bolsa concedida ao primeiro autor durante a elaboração deste trabalho; à Fundação de Amparo à Pesquisa do Estado de São Paulo (FAPESP) pelo auxílio à pesquisa fornecido (proc. 01/12364-0).

\section{Referências bibliográficas}

Barroso, G.M.; Morim, M.P.; Peixoto, A.L. \& Ichaso, C.L.F. 1999. Frutos e sementes: morfologia aplicada à sistemática de dicotiledôneas. Viçosa, Imprensa Universitária (UFV).

Bobrov, A.V.F.CH.; Endres, P.K.; Melikian, A.P.; Romanov, M.S.; Sorokin, A.N. \& Bejerano, A.P. 2005. Fruit structure of Amborella trichopoda (Amborellaceae). Botanical Journal of the Linnean Society 148: 265-274.

Castro, M.A. 1986. Anatomia del fruto de Araujia horotorum E. Fourn. (Asclepiadaceae). Parodiana 4: 195-203.

Cronquist, A. 1981. An integrated system of classification of flowering plants. New York, Columbia University Press.

Dave, Y. \& Kuriachen, P.M. 1987. Structure and development of stomata on the fruit wall of Calotropis procera (Arr.) R. BR. Proceedings of the Indian Academy of Sciences (Plant Sciences) 97: 449-456.

Dave, Y. \& Kuriachen, P.M. 1990. Structure and development of the follicle of Asclepias curassavica L. (Asclepiadaceae) with note on dehiscence. Beitrage zur Biologie der Pflanzen 65: 109-122.

Dave, Y. \& Kuriachen, P.M. 1991. Comparative anatomical characters of Periplocaceae follicles and their taxonomic significance. Feddes Repertorium 102: 63-68.

Demarco, D.; Kinoshita, L.S. \& Castro, M. de M. 2006. Laticíferos articulados anastomosados - novos registros para Apocynaceae. Revista Brasileira de Botânica 29: 133-144.

Desvaux, N.A. 1813. Essai sur less differens genres de fruits des plantes phanerogames. Journal de Botanique, Apliquée à la Agriculture, à la Pharmacie, à la Médecine et aux Arts 2: $161-183$.

Dumortier, B.C. 1835. Essai carpographique présentant une nouvelle classification des fruits. Bruxelles, Imprimeur de I' Académie Royale.

Endress, M.E. \& Bruyns, P.V. 2000. A revised classification of the Apocynaceae s.1. The Botanical Review 66: 1-56. 
Esau, K. 1965. Plant anatomy. $2^{\text {nd }}$ ed. Tokyo, Toppan Company Ltd.

Evert, R.F. 2006. Esau's plant anatomy. New Jersey, John Wiley \& Sons, Inc.

Fahn, A. \& Zohary, M. 1955. On the pericarpial structure of legumen, its evolution and relation to dehiscence. Phytomorphology 5: 99-111.

Fahn, A. 1979. Secretory tissues in plants. London, Academic Press.

Fahn, A. 1990. Plant anatomy. Oxford, Pergamon Press.

Farrel, B.D.; Dussourd, D.E. \& Mitter, C. 1991. Escalation of plant defense: do latex/resin canals spur plant diversification? American Naturalist 138: 881-900.

Gaertner, J. 1788. De fructibus et seminibus plantarum. Typis Academiae Carolinae, Stuttgart.

Gerrits, P.O. \& Smid, L. 1983. A new, less toxic polymerization system for the embedding of soft tissues in glycol methacrylate and subsequent preparing of serial sections. Journal of Microscopy 132: $81-85$

Gupta, V. \& Lamba, L.C. 1981. Sclereids in the endocarp of Rauvolfia serpentina (L.) Benth ex Kurz. Proceedings of the Indian Academy of Sciences - Plant Sciences 90: 79-84.

Hunter, J. R. 1994. Reconsidering the functions of latex. Tree 9: 1-5.

Hutchinson, J. 1969. Evolution and phylogeny of flowering plants. London, Academic Press.

Jensen, W.A. 1962. Botanical histochemistry. San Francisco, W.H. Freeman and Company.

Johansen, D.A. 1940. Plant microtechnique. New York, McGrawHill Book Company.

Judd, W.S.; Campbell, C.S.; Kellogg, E.A. \& Stevens, P.F. 2002. Plant systematics: a phylogenetic approach. Sunderland, Sinauer Associates Inc. Publishers.

Kinoshita, L.S. (coord.). 2005. Apocynaceae. Pp. 35-91. In: M.G.L. Wanderley; G.J. Shepherd; T.S. Melhem \& A.M. Giulietti (orgs.). Flora fanerogâmica do estado de São Paulo. v. 4. São Paulo, FAPESP/HUCITEC.

Kuriachen, P.M. \& Dave, Y. 1989. Structure and development of fruit wall ornamentations in Pergularia daemia (Forsk.) Chiov (Asclepiadaceae). Proceedings of the Indian Academy of Sciences (Plant Sciences) 99: 15-20.

Kuriachen, P.M.; Dave, Y. \& Thomas, V. 1991. Development, structure and dehiscence of follicles of Calotropis procera (Ait.) R. Br. (Asclepiadaceae). Korean Journal of Botany 34: 107-112.

Kuriachen, P.M.; Thomas, V. \& Dave, Y. 1990. Morphohistogenic studies in the follicle of Tylophora dalzellii HK. F. Phytomorphology 40: 349-347.

Kuriachen, P.M.; Thomas, V. \& Dave, Y. 1992. Taxonomic and phylogenetic significance of fruit walls in Asclepiadaceae. Feeds Repertorium 103: 179-193.

Kuriachen, P.M.; Thomas, V. \& Dave, Y. 1993. Ultrastructural studies of the ovary wall and pericarp of Asclepias curassavica L. II Mesocarp development. Feddes Repertorium 104: 227-235.
Lindley, J. 1832. An introduction to botany. London, Longman, Brouwn, Green \& Longman.

Linnaeus, C. 1751. Philosophia botanica. Godofr Kiesewetter, Stockholm.

Linnaeus, C. 1759. Systema naturae II. Laurentii Salvii, Holmiae.

Mahran, G.H.; Saber, A.H. \& Rizkallah, M.M. 1967. Calotropis procera (Ait.) R. Br. IV. The fruits, its macro - and micromorphology. Journal of Pharmacological Sciences of United Arab Republic 9: 81-100.

Mirbel, C.F. 1813. Nouvelle classification des fruits. Nouveau Bulletin des Sciences/ par la Société Philomatique de Paris 3: 313-319.

O’Brien, T.P.; Feder, N. \& Mc Cully, M.E. 1964. Polychromatic staining of plant cell walls by toluidine blue O. Protoplasma 59: 368-373.

Pearse, A.G.E. 1980. Histochemistry theoretical and applied. v.II, $4^{\text {th }}$ ed. Longman Group Limited.

Potgieter, K. \& Albert, V.A. 2001. Phylogenetic relationships within Apocynaceae s.l. based on $\operatorname{trn} \mathrm{L}$ intron and $\operatorname{trn} \mathrm{L}-\mathrm{F}$ spacer sequences and propagule characters. Annals of Missouri Botanical Garden 88: 523-549.

Rio, M.C.S. \& Kinoshita, L.S. 2005. Prestonia (Apocynaceae) do Sul e Sudeste do Brasil. Hoehnea 32: 233-258.

Roth, I. 1977. Fruits of angiosperms: encyclopedia of plant anatomy. Berlin, Gebrüder Borntraeger.

Souza, L.A. 2006. Anatomia do fruto e da semente. Ponta Grossa, UEPG.

Souza, L.A.; Iawazaki, M.C. \& Oliveira, R.C. 2004. Morfologia do fruto e da semente em desenvolvimento de Asclepias curassavica L. (Asclepiadaceae). Insula 33: 39-49.

Souza, L.A. \& Moscheta, I.S. 1992. Morfo-anatomia do fruto e da plântula de Aspidosperma polyneuron M. Arg. (Apocynaceae). Revista Brasileira de Biologia 52: 439-447.

Spjut, R.W. 1994. A systematic treatment of fruit types. Memoirs of The New York Botanical Garden 70: 1-82.

Thomas, V. \& Dave, Y. 1991. Structure and development of follicles of Nerium indicum Mill. (Apocynaceae). Feddes Repertorium 102: 399-407.

Thomas, V. \& Dave, Y. 1994. Significance of follicle anatomy of Apocynaceae. Acta Societatis Botanicorum Poloniae 63: 9-20.

Von Teichman, I. \& Van Wyk, A.E. 1991. Trends in the evolution of dicotyledonous seeds based on character associations, with special reference to pachycalazy and recalcitrance. Botanical Journal of the Linnean Society 105: 211-237.

Wardrop, A.B. 1983. The opening mechanism of follicles of some species of Banksia. Australian Journal of Botany 31: 485-500.

Zala, J.V.; Patel, N.D. \& Dave, Y.S. 1976. Structure of the developing and dry pericarp of Catharanthus roseus (Apocynaceae). Flora 165: $335-360$. 